\title{
ARICA Y PARINACOTA, UN PAISAJE CULTURAL SUR ANDINO DE SIGNIFICADO UNIVERSAL ${ }^{[*]}$
}

\author{
ARICA Y PARINACOTA, \\ A SOUTH ANDEAN CULTURAL LANDSCAPE OF UNIVERSAL SIGNIFICANCE \\ ÁNGEL ALBERTO GUILLÉN CÁRDENAS ${ }^{[(*)}$ \\ Fecha de recepción: 02 de abril de 2016 \\ Fecha de aprobación: 15 de mayo de 2016
}

\section{RESUMEN}

Las tendencias actuales de la XV Región muestran un ostensible descenso demográfico del entorno rural, y una desproporcionada urbanización de la costa en desmedro del área rural, aimara y andina. La activación del proyecto "Paisaje Cultural de Arica y Parinacota", auspiciada por el Gobierno Regional de Arica y Parinacota (GORE) dentro del Programa de Puesta en Valor del Patrimonio (PPVP) de la Subsecretaría de Desarrollo Regional (SUBDERE), e impulsada desde la Fundación Altiplano Monseñor Salas Valdés, ofrece una alternativa para el desarrollo territorial del norte chileno.

Tanto la valoración como el reconocimiento de Arica y Parinacota como primer paisaje cultural andino de Chile son propósitos importantes que impulsan el desarrollo regional. La estructuración conceptual, metodológica y operativa de la región como Paisaje Cultural traería una serie de beneficios: fomentaría un imaginario innovador, mejoraría la relación con el patrimonio ancestral, integraría a las comunidades aimaras y andinas, generaría una visionaria cultural del territorio, y se asociaría a i) la preservación ancestral de dicho patrimonio, ii) los valores identitarios, iii) la política pública y iv) la utilización de diversas escalas proyectuales.

\section{PALABRAS CLAVE}

Paisaje Cultural, comunidad, territorio

\section{ABSTRACT}

The current trends in the $15^{\text {th }}$ region show an ostensible demographic decline of rural areas and a disproportionate urbanization of the coast in detriment of the rural, Aymara and Andean areas. The activation of the Cultural Landscape of Arica and Parinacota project, sponsored by the Regional Government within the PPVP of SUBDERE and promoted by Altiplano Foundation, is an alternative for territorial development in northern Chile.

The appreciation as well as the recognition of Arica and Parinacota as the first Andean Cultural Landscape of Chile is an important goal that will boost regional development. The conceptual, methodological and operational structure of the region as a Cultural Landscape could result in several benefits: enhance its innovative image, improve the relationship with the ancestral heritage, integrate the Aymara and Andean communities, generate a visionary culture of the territory, link the territory to sustainability, articulate identity values, add to the public policy, and strengthen the use of various projective scales.

\section{KEYWORDS}

Cultural Landscape, community, territory

${ }^{*}$ ) El presente artículo visualiza un concepto territorial alternativo para la XV Región de Arica y Parinacota-Chile. Tiene su germen en una iniciativa compartida entre el Gobierno Regional de Arica y Parinacota, la Subsecretaría de Desarrollo Regional y la Fundación Altiplano MSV, a través del programa 'Arica y Parinacota como Paisaje Cultural de América', iniciativa que empezó en 2015 y continúa a la fecha (2016). La interacción y socialización con las comunidades e instituciones público-privadas de la región, en mesas generativas específicas asesoradas por importantes especialistas nacionales e internacionales, ha colegido en la comprensión y propuesta de un escenario patrimonial que resalta el significado universal del borde septentrional de Chile. ${ }^{* *}$ ) Arquitecto, UNSA, Arequipa, Perú. MSc. Desarrollo Sustentable, UnLA, Buenos Aires, Argentina. Especialidad en Conservación y Rehabilitación del Patrimonio Arquitectónico, UCSM, Arequipa, Perú. Especialización en Gestión del Patrimonio Mundial, Ministerio de Cultura, Madrid, España. Ejercicio profesional en Chile y Perú: INC, AECID y Fundación Altiplano MSV, con actuaciones en más de 20 conjuntos monumentales. En FAMSV-Chile, ha sido Asesor, Jefe del Taller de Arquitectura y, actualmente se desempeña como Encargado de Patrimonio. Publicaciones en autoría y coautoría. Integrante del equipo formulador del Paisaje Cultural de Arica y Parinacota. Además, ha sido jurado del Fondo Nacional de Patrimonio de Chile 2015 e integrante del equipo consultor para el replanteo del Modelo de Gestión "Ruta de las Misiones"-BID Chile. Actualmente es el coordinador general de la restauración integral del Templo San Andrés de Pachama. Contacto: angel.guillencardenas@gmail.com 


\section{Reflexiones iniciales}

Entre el siglo XX y el siglo XXI han acontecido diversos sucesos, pero casi ninguno de ellos ha tenido un resultado proactivo para los paisajes culturales. Aún son épocas impregnadas de violencia humana que se proyectan con igual voracidad hacia los paisajes y territorios. En términos de normatividad, legislación y protección patrimonial (incluida la paisajística), la activación y actuación de la UNESCO se tornó referencial. Uno de aquellos conceptos resemantizados tiene directa relación con la belleza y utilidad de los escenarios acondicionados por el hombre; surge así la categoría patrimonial del Paisaje Cultural, respaldada por atributos de significado universal.

En lo concreto la categoría de 'Paisaje Cultural', promovida por UNESCO, no ha merecido un incremento sustantivo de sitios sudamericanos en la Lista del Patrimonio Mundial. Los paisajes culturales andinos han sido prácticamente soslayados, con la excepción de la Quebrada de Humahuaca (en el norte argentino); otros lugares como el Valle del Colca, el Valle Sagrado de los Incas, el entorno circun-lacustre del lago Titicaca, la cuenca del Osmore en Moquegua o el conjunto precordillerano del Huaylillas en Arica y Parinacota (en Chile), entre otros, son puntos relevantes de la fisonomía paisajística sur andina que poseen los atributos suficientes para un ulterior reconocimiento universal.

Arica y Parinacota como Paisaje Cultural de América convalida un patrimonio proverbial, resalta la complejidad del escenario más árido del orbe, testifica una presencia humana milenaria, y respalda una deseabilidad de arraigo y permanencia; es una totalidad que ejemplifica la sabiduría y persistencia del hombre, en un medio singularmente bello y conmovedoramente hostil.

En la XV Región el tránsito de paisaje natural a cultural sugiere un enorme esfuerzo compartido que superó las dificultades medioambientales gracias a una prodigiosa capacidad creativa y adaptativa. Para comprender asertivamente las dinámicas territoriales regionales es necesario observar holística e integralmente el territorio. Una figura coincidente en el esquema de la estructura paisajística persiste a través de la articulación longitudinal y transversal de sus componentes.

El paisaje cultural de Arica y Parinacota puede definirse como un lugar de reencuentro entre el hombre andino y su territorio. La invitación propone valorar sus bondades ancestrales dentro de un ámbito de interacción e integración comunitaria dispuesto en medio de una escenografía sugerente. En dicho lugar actitudes y aptitudes tanto consensuadas como proactivas podrían prevalecer como mecanismos de cohesión cultural comprometidos con la continuidad, preservación, innovación y desarrollo.

\section{Prólogo}

Las tendencias actuales de la XV Región Arica y Parinacota-Chile, muestran i) un descenso demográfico del entorno rural que resalta la convivencia dialéctica entre un paisaje dinámico y pro-activo, y un paisaje ralentizado e inercial; ii) una tendencia asimétrica que expone una desproporcionada urbanización de la costa ${ }^{1}$ en contraste con un letargo evidente del área rural aimara y andina.

La activación del proyecto Paisaje Cultural de Arica y Parinacota está auspiciada por el Gobierno Regional de Arica y Parinacota como parte del Programa Puesta en Valor del Patrimonio de la SUBDERE, e impulsada conceptual y operativamente desde Fundación Altiplano MSV como parte de una política pública patrimonial; es una alternativa ingeniosa, leve y provechosa para el desarrollo territorial regional.

1. La ciudad de Arica cuenta con un $92 \%$ de la población regional. 
Tanto la autovaloración como el reconocimiento de las singularidades y potencialidades de Arica y Parinacota como primer paisaje cultural andino de Chile y uno de los más importantes de América son loables ideas-fuerza. Se mostrarían como un vehículo transformador del presente, y se obtendría colateralmente en el mediano y largo plazo un futuro sustentable. El principal componente del paisaje regional está en su gente (comunidades de procedencia aimara), y en torno a ellos se requeriría girar y coincidir cada uno de los propósitos activados.

¿Cuánto y qué se espera, entonces? En primer lugar, la reactivación productiva del paisaje cultural demanda ejes temáticos capaces y suficientes para materializarse en su espacio proyectual, que consiste en lo surandino, con Bolivia y Perú; el ambiente; lo etnográfico; las rutas longitudinales y transversales; los eventos históricos; y la espiritualidad. También requiere cotejar el programa de un territorio pródigo en simbolismos con las demandas de un enriquecido programa político contemporáneo. Es una materia inquietante a la que le urgen visiones amplias y consensuadas que solo las pulsaciones del territorio (construcción social y física) pueden mostrar.

La estructuración conceptual, metodológica y operativa de la XV Región de Arica y Parinacota como Paisaje Cultural (PC) tiene una serie de beneficios: fomenta un imaginario innovador, fortalece el desarrollo, se imbrica potentemente con el patrimonio, facilita la integración de las comunidades y genera una visionaria cultura del territorio.

La gestión del Paisaje Cultural de Arica y Parinacota permitirá i) una lectura idónea de los indicadores de desarrollo; ii) el reconocimiento de las verdaderas demandas poblacionales; iii) la identificación de diversas oportunidades proyectuales; iv) la proposición de horizontes espacio-temporales medibles; y v) la definición de responsabilidades institucionales en la gestión paisajística.

Los lineamientos paisajísticos contemplan: i) la interpolación y extrapolación de indicadores territoriales; ii) la consolidación y ratificación de la inversión en la recuperación y puesta en valor del patrimonio cultural como una política pública nacional-regional; y iii) la integración de las actuaciones patrimoniales dentro de un esquema mayor (manejo de escalas múltiples), donde se estimule la transversalidad, competitividad, inversión e innovación territorial.

\section{Paisajes culturales andinos}

Los paisajes y territorios han adquirido en el presente una importancia capital para enfrentar con éxito las tareas y retos del futuro; así se pueden resignificar sus contenidos y asumirlos, en consecuencia, como elementos esenciales para realizar proyectos en el ambiente.

En 1998, en Arequipa y Chivay (Valle del Colca), se reunieron los expertos convocados por el Centro del Patrimonio Mundial de la UNESCO para tratar el caso de los paisajes culturales andinos. De los diez casos que fueron presentados en la reunión de 1998, cuatro de ellos tenían alguna relación con el Paisaje Cultural Alto Andino de Arica y Parinacota: el Parque Nacional Sajama (Bolivia), Ayquina y Toconce, y el Oasis de San Pedro de Atacama (Chile), que comparten cercanía y contextos histórico-culturales similares; quedó el Valle del Colca (Perú) como referencial.

El grupo de expertos enunció algunas preocupaciones específicas -aún no resueltasrelacionadas con el declive del carácter dinámico de los paisajes y las pocas capacidades de gestión instaladas.

Por otra parte, lo identitario como un eje matricial común en los territorios del denominado espacio surandino ha coincidido en una serie de ámbitos de la construcción de paisajes culturales; en ellos se comparten rasgos comunes, diversos y singulares, 
que los caracterizan en apariencia, contenido y forma. Ese contexto, además de enmarcar el curso y decurso del paisaje cultural regional, ha sido y es motivo de referencia fundamental para la ponderación de los contenidos ambientales e históricos de esta parte de América.

\section{Los paisajes culturales del espacio surandino, rasgos comunes, diversos y singulares}

El espacio occidental surandino es uno de los ámbitos sudamericanos con mayor multiplicidad ambiental y geomorfológica. Su identidad paisajística es coincidente y concurrente con las dinámicas culturales, económicas, sociales y políticas que ha afrontado el territorio en el curso y decurso de los procesos de adaptación humana, y configuración-reconfiguración geopolítica.

En todos los casos, sus poblaciones milenarias -esencialmente de procedencia aimara y quechua- llegaron a dominar con eficiencia un entorno hostil, lo que propició un desarrollo de alto nivel.

Las comunidades andinas adquirieron un conocimiento de los recursos ambientales y una convicción premeditada para transformar parajes naturales en paisajes culturales.

En el tiempo presente, el panorama del territorio surandino expone una variedad de paisajes culturales: algunos relictos, otros evolutivos y, en casos específicos, unos asociativos. Funcionan como testimonio de un proceso histórico dilatado, y sujeto a especificidades regionales $\mathrm{y} / \mathrm{o}$ nacionales.

En el campo de la sostenibilidad, los paisajes culturales sur no han podido eludir los cambios dramáticos mundiales; por tanto, la posibilidad de extravío de sus rasgos comunes, diversos y singulares es alta. Convendría identificar de una manera compartida -transfronteriza- sus amenazas, valores y potencialidades para asegurar la continuidad espacio-temporal de sus entornos.

El aporte de los paisajes culturales surandinos a la conservación de áreas naturales de significado nacional e internacional es de primer orden. Resaltan: i) el Valle del Colca, y la Reserva Nacional de Salinas y Aguada Blanca (Arequipa, Perú); ii) el Parque Nacional de Sajama y las comunidades carangas (Oruro, Bolivia); y iii) El Parque Nacional del Lauca (precordillera de Arica y Parinacota, Chile).

En todos los casos, desde los paisajes surandinos, emerge la posibilidad de apelar a mecanismos innovadores pero respetuosos de matrices tecnológicas ancestrales que tendrían la capacidad de regenerar a sus comunidades, lo que facilitaría en la proporción debida el arraigo y retorno poblacional.

Un rasgo común, concurrente y singular de los paisajes surandinos está en su universalidad y representatividad.

Históricamente, el espacio surandino fue articulado infraestructuralmente por una amplia red de caminos y rutas que facilitaron la integración longitudinal y transversal de mercancías y gente. Pese a mantener elementos identitarios compartidos, los paisajes surandinos requieren adecuarse a una comprensión y aplicación de escalas territoriales. Debido a la magnitud de sus ámbitos es oportuno definir las dimensiones y contenidos a manejar, conservar e innovar. El patrimonio material e inmaterial sintetizado en el aporte humano es el principal soporte identitario de los espacios surandinos.

Una adecuación y preparación anticipativa de los paisajes para fines turísticos debe observarse desde una perspectiva integral, la cual incidiría en el sentido interpretativo del territorio. 


\section{El paisaje transfronterizo sur andino}

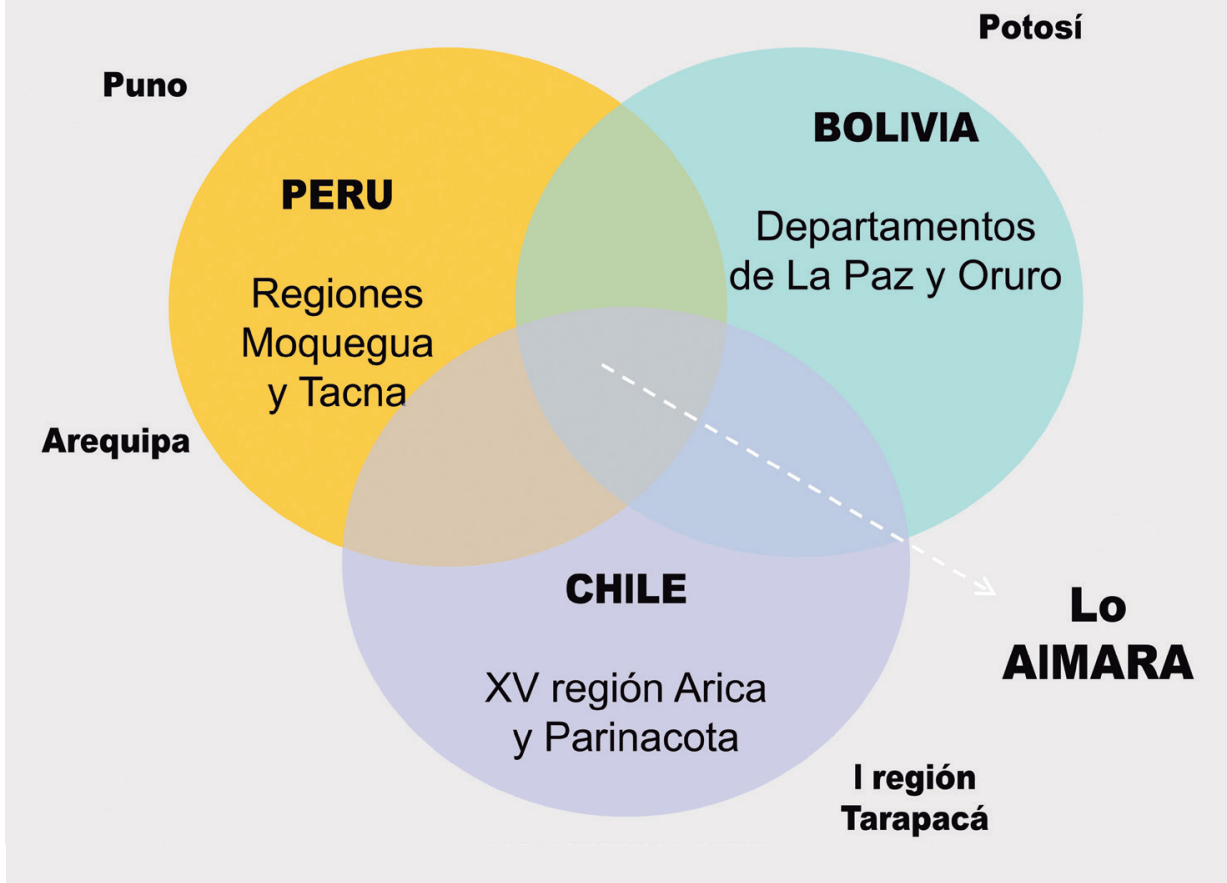

Bajo el lente comparativo con otros paisajes culturales surandinos, podrían referenciarse los siguientes casos:

a) El Valle del Colca, ubicado en la provincia de Caylloma (Arequipa, Perú), que muestra más de diez mil hectáreas de terrazas agrícolas acondicionadas en las faldas de las montañas que confluyen hacia el río Colca. Estas son un prodigio humano y de ingeniería que demuestra el ingenio de sus poblaciones locales: collaguas y cabanas, autores y actores vivos de la modelación del territorio. La pervivencia centenaria de tales grupos indígenas no fue ajena a las influencias y determinismos que imperaron a partir de la dominación incásica, la colonización europea y la ausencia republicana. Pese a todo, los grupos humanos locales han sido capaces de trascender en el tiempo con sus formas y usos culturales de inigualable valía.

b) El Parque Nacional de Sajama, ubicado en el departamento de Oruro, Bolivia, es un típico escenario altiplánico de condición hostil para la vida en general; sin embargo, por razones culturales e históricas relacionadas con la colonización de pisos ecológicos más bajos ubicados en la parte occidental (actualmente Arica y Parinacota), ha propiciado desde hace centurias la instalación de diversos grupos humanos, entre los que destacan los carangas, de procedencia aimara.

c) Más hacia el sur, en pleno desierto de Atacama, en Antofagasta, Chile, se perciben dos casos cercanos, pero envueltos en circunstancias puntuales: Ayquina y Toconcé son dos comunidades que aún habitan en un entorno agreste pero significativo en términos culturales. Se distingue el nivel de arraigo y persistencia territorial; ambas se sustentan en la mantención de las formas y usos ancestrales. Por otra parte, aparece San Pedro de Atacama, que singulariza un ecosistema de oasis de extrema fragilidad, y que actualmente afronta una pertinaz presión minera y turística que ha impactado en su esencia ambiental y cultural (ver Figura 1).
Figura 1. El paisaje cultural transfronterizo

Fuente: Ángel Guillén, 2016. 


\section{Construcción del imaginario paisajístico regional}

Se ha verificado que ha habido presencia humana en los Altos de Arica durante diez mil años; esta encontró su mayor y mejor fundamento para el arraigo en la existencia de un espacio agreste pero pródigo en recursos ambientales de conexión longitudinal y transversal. La cordillera de los Andes es el divisor territorial entre los bordes altiplánicos occidental y oriental, respectivamente.

Los carangas, un señorío aimara de elevada demografía que radicaba en la parte oriental de la cordillera (anteriormente Alto Perú), ejerció una influencia directa en la estructuración del imaginario paisajístico de Arica y Parinacota. Posteriormente, los incas aportaron su capacidad de síntesis para precisar las características inconfundibles del espacio geográfico: andenes, caminos, tambos y ushnus.

Lucas Martínez Vegazo, un antiguo compañero de armas de Francisco Pizarro, recibió desde Cusco, mediante una cédula del 4 de agosto de 1535, la 'encomienda' que comprendía el territorio dispuesto entre los valles de Azapa y Lluta, incluida Tarapacá. La visión colonial del paisaje estaba planteada. Aquel ámbito cultural contenía una relación específica de caciques, pueblos, valles, estancias e indios tributarios.

Una 'verticalidad escalonada' logró mantenerse como parte del imaginario paisajístico durante el periodo temprano-colonial. La noción del mallku o centro de poder prevaleció en la parte posterior del macizo andino (en el actual departamento de Oruro); mientras tanto, los caciques conservaron su predominio político desde centros secundarios precordilleranos; en la franja costera, por otro lado, permanecieron pequeñas poblaciones encabezadas por 'principales'. Esa noción equilibrada de la distribución demográfica y territorial, ambiental y paisajísticamente idónea, varió en la medida que la ciudad y puerto de Arica empezó a validar su rango hegemónico, y modificó sistemáticamente el paisaje rural.

En suma, la construcción del imaginario paisajístico regional puede sintetizarse en cinco aspectos:

\section{A) Excentricidad de Arica:}

Hubo un momento diferente para la articulación territorial de la actual región Arica y Parinacota, en la cual la visión andina mantuvo las interrelaciones y flujos culturales, sociales y productivos que dinamizaban su paisaje cultural. La conversión de Arica en el principal puerto de Potosí, y en uno de los más importantes de la costa del Pacífico meridional, definió su impronta urbana, preponderante en la escala regional.

B) Conquista del interior:

Las primeras misiones andinas se ordenaron desde Arica, y avanzaron indistintamente por los valles de Azapa y Lluta a través de los antiguos caminos prehispánicos. Aparecieron iglesias y capillas por doquier en clara alusión al nuevo credo vigente. Se dispusieron los puntos de avanzada territorial.

C) Centralidad andina de Belén:

La avanzada endógena sirvió para confirmar la existencia longeva de modos y formas de estructuras prehispánicos. Un caso fue dispuesto en el mayor espacio de concentración demográfico y productivo, la 'Sierra del Huaylillas': el pueblo de Belén (antigua Tocoroma). Para llegar a este pueblo desde la costa, se tenía que ascender a través de la quebrada marcada por el río Azapa, cruzando por los emblemáticos asentamientos de Humagata y Livílcar. Era todo un viaje transversal que certificaba las relaciones ancestrales de complementariedad vertical andina y, en este caso, aimara. Durante la Colonia, en medio de un territorio en proceso de cristianización, el pueblo de Belén se convirtió en un nodo neurálgico para la administración religiosa y colonial; se tornó en un lugar vital desde donde se decidía la construcción de complejos religiosos. 
D) La hegemonía de lo artificial:

Los dilemas suscitados para una adecuada gobernanza del espacio regional colonial, amenazado por focos insurreccionales, concluyeron en la validación del pueblo de Codpa como otro de los enclaves del interior. Fue necesario y oportuno para la administración colonial y religiosa, una decisión estratégica que jerarquizó a otro lugar fundamental en la distribución de los recursos paisajísticos de las cuencas de Codpa y Camarones.

E) La doble transición decimonónica:

El paso de la Colonia a la República no estuvo exento de conflictos y subsecuentes fragmentaciones. La primera fragmentación, derivada del tránsito entre Virreinato y República del Perú, no marcó cambios visibles en la fisonomía del paisaje regional, salvo por la consolidación de la hegemonía urbana de Tacna sobre el puerto de Arica. Las relaciones de vecindad, complementariedad e intercambio se multiplicaron en antinomia: los pueblos del entorno rural seguían olvidados. Las calidades portuarias de Arica estaban dispuestas para otros afanes y sus movimientos comerciales aún la mostraban como el tercer puerto del suroccidente de América Meridional.

La segunda fragmentación está conectada a la Guerra del Pacífico. La conflagración fue un punto de inflexión subcontinental que, en el caso de Arica, se patentó en un cambio de estatus estadual. Tal imperativo incidió objetiva y subjetivamente en las formas sociales y culturales preestablecidas.

\section{F) La urbanización de Arica:}

El siglo XX confirma la progresiva e indeclinable urbanización de Arica. Es el tiempo donde todas las expectativas de desarrollo se volcaron a la ciudad. Una suma de hechos alentó un imaginario paisajístico con formas citadinas. El 'puerto libre' y la 'junta de adelanto' han quedado impregnados como la mayor y mejor remembranza de una Arica idílica. Es el tiempo que alentó la urbanidad en contraste con el abandono sin retorno de lo rural.

G) La búsqueda identitaria:

Se trata de tiempos de búsqueda y reencuentro. Surgió, en medio de todo, una oportunidad concreta para desplegar recursos y subsecuentes interacciones socioculturales con las comunidades. No son falacias: este ha sido un tiempo para promover el patrimonio territorial regional, sobre todo en las comunidades andinas del interior. Aparece el PPVP, que se alentó inicialmente desde el BID en conjunto con el Gobierno de Chile, a través de la SUBDERE conectado desde el Gobierno Regional de Arica; contribuye al fortalecimiento, recuperación y puesta en valor del patrimonio. Para ello la Fundación Altiplano MSV, una entidad sin fines de lucro, actúa como la subunidad ejecutora patrimonial.

El antiguo paisaje cultural, dinámico y concurrente, ha sido seriamente amenazado, al punto de encontrarse en medio de un proceso inercial difícil de revertir. La esperanza puesta y dispuesta en los logros que podrían obtenerse desde una reconceptualización programática y operativa enmarcada en el espectro de un gran paisaje cultural regional está calando en el pensamiento e interioridad de la población; este es un indicador positivo en medio de la incertidumbre. El trabajo desplegado es interesante y medible, y tiene resultados efectivos en pro del paisaje regional; para ello, fue necesario ir más allá de las restauraciones. En suma, se necesitarán muchos recursos cuantitativos y cualitativos para proseguir con el propósito. La diferencia entre este modelo contemporáneo, y aquellos coloniales y republicanos, radica en su visión y prospectiva que parte de las necesidades, el reconocimiento del valor, las actuaciones patrimoniales y el acompañamiento permanente a las comunidades andinas. 
devenir Vol. 3, N5, ENERO- JUNIO 2016, PP. 45-66 - ESTUDIOS | ISSN 2312-7570

UNIVERSIDAD NACIONAL DE INGENIERÍ, LIMA

Figura 2. Región Arica y Parinacota Fuente: Ángel Guillén, 2016.

\section{Sistema territorial regional}

\section{SUBSISTEMA TERRITORIAL}

Comuna: General Lagos

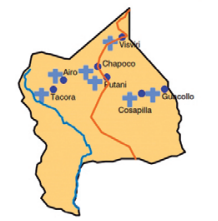

N.M.
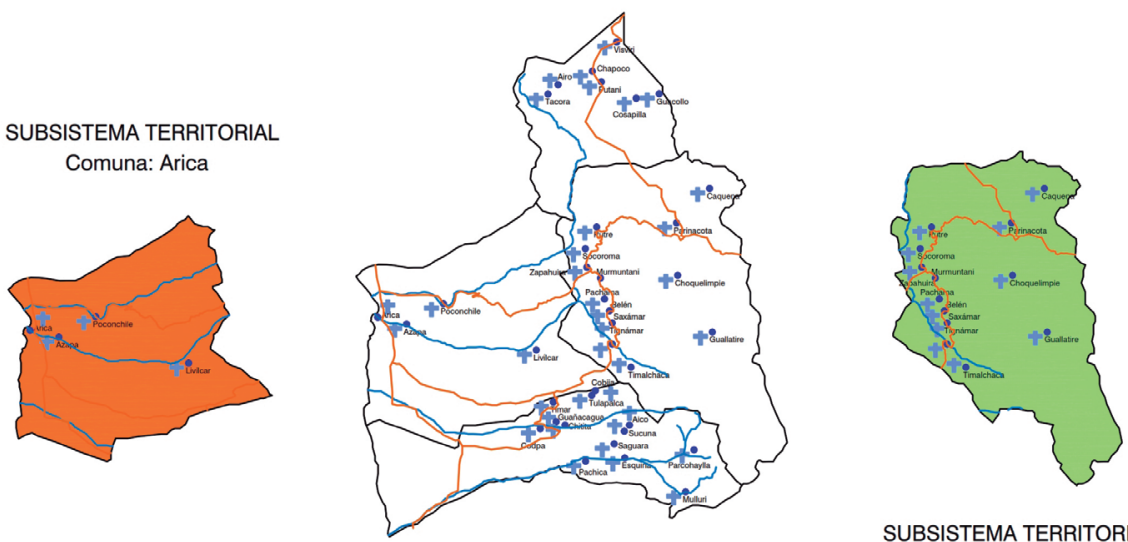

SUBSISTEMA TERRITORIAL

Comuna: Putre

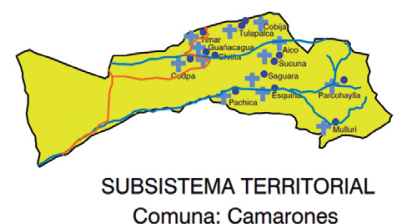

ComunSTE: Camarones
ComA TERRITOR

\section{Caracterización regional y tendencias actuales}

La región tiene una superficie de 16,898.6 km², que representa el $2.24 \%$ de la superficie de Chile. Su población es de 189,644 habitantes, equivalente al 1.24\% del país. El 93\% de la población es urbana y el $7 \%$ es rural. La capital regional es la ciudad de Arica que concentra el $98.7 \%$ de la población. Arica y Parinacota conforman el espacio territorial de Chile con mayor migración rural.

Los recursos hídricos regionales son limitados: se generan principalmente en las zonas de mayor altura, sobre los 3,000 m.s.n.m., en las cuencas altas de los ríos Lluta y San José, así como en el Altiplano. La producción agrícola está sustentada en el cultivo de olivos: 1,500 hectáreas representan un $9.7 \%$ de la superficie plantada. La minería no es de gran escala y existe una importante conciencia respecto a su incidencia en el desarrollo regional (ver Figura 2).

Por otra parte, las áreas de protección ambiental son cuantitativa y cualitativamente generosas: los Monumentos Naturales Quebrada de Cardones y Salar de Surire, la Reserva Nacional Las Vicuñas y el Parque Nacional del Lauca (Reserva de la Biosfera). Su patrimonio más importante está en la pervivencia de una población importante de ascendencia aimara que ha ocupado el territorio a lo largo de los siglos, lo que plasma testimonios tangibles e intangibles de gran valía. 


\section{Procesos históricos territoriales}

La implicancia ecológica y económica del paisaje cultural de los altos de Arica fue determinante para la estructuración de un espacio territorial de ocupación humana continua desde épocas prehispánicas, cuyo motivo de enraizamiento estuvo en el uso sistemático de diversos pisos ecológicos.

Las evidencias tempranas de presencia humana en los altos de Arica se remontan a los diez mil años antes de Cristo. Los primeros grupos humanos prefirieron ubicarse en los sectores altiplánicos y precordilleranos.

Un punto importante en la configuración territorial del norte alto andino fue acotado por el imperio Tiwanacu, que a partir de 500 d.C. amplió su radio de acción social, religioso y cultural hacia el borde occidental de los Andes. Tuvieron un poco más de 500 años de influencia nítida; en este tiempo plasmaron su arquitectura, conjuntos urbanos y sistemas hidráulicos, y concretizaron una significativa frontera agrícola que les permitió, a través de colonias instaladas en los valles costeros, mejorar su dieta y afianzar su seguridad alimentaria.

Ideológicamente, la desaparición de los Tiwanaku generó un obligado replanteo territorial de índole ambiental; en dicho momento gran parte de las poblaciones aimaras altiplánicas optaron por ocupar las partes bajas del borde occidental. De esta manera, las relaciones de convivencia-conflicto se instalaron durante unos 300 años, episodios que fueron aprovechados por los nuevos señoríos aimaras que se reinventaron como lupacas, carangas, pacajes y quillacas.

El aporte incaico en el modelaje del paisaje cultural de los altos de Arica se plasmó de distintas formas: la optimización del sistema hidráulico; una discreta ampliación de la frontera agrícola; la adaptación de poblados, colcas y tambos; y la jerarquización de la red vial imperial (qhapaq ñan).

El arribo de los españoles en 1532 cierra el capítulo ambiental concerniente a la concepción y manejo del paisaje cultural amerindio. En 1540, Pedro de Valdivia partió desde Cusco para concretizar la conquista de Chile. El paso de los meses luego ratificó el protagonismo de Arica y sus altos como punto esencial para el éxito de tan ambiciosa empresa. La consagración histórica de Arica fue dispuesta por el virrey Francisco de Toledo al denominarla puerto oficial de Potosí (en la Ruta de la Plata).

Solo el paso de los años y siglos reconfirmarían la gravitación fundamental de Arica y sus altos como espacios territoriales que asumieron desde su aparición una posición de bisagra o interfase, tanto transversal como vertical, en la América suroccidental; esto los convirtió, durante el periodo colonial, en un pívot comercial que disputó su hegemonía con el Callao y Valparaíso.

En el periodo decimonónico, el puerto de Arica ya estaba consolidado. La gesta independentista sudamericana derivó en el desmembramiento del Alto Perú y la creación de la República de Bolivia. En términos operativos, Arica mantuvo vigentes sus relaciones ancestrales con las comunidades altiplánicas, lo que afianzó su rango como puerto principal del hemisferio suroccidental.

El imaginario de un lugar afortunado para el desarrollo territorial fue puesto a prueba por el terremoto y maremoto del 13 de agosto de 1868; en tan solo minutos, las ondas sísmicas y marinas derivaron en destrucción y desolación.

La guerra del Pacífico fue importante, nuevamente, para el destino de Arica. Al integrarse dentro del territorio chileno, tuvo que afrontar una larga espera de formalizaciones: desde 1883 hasta 1929. Los años subsiguientes, entre las décadas de 1930 y 1940, se produjo una importante ola migratoria de las comunidades rurales hacia la ciudad. 


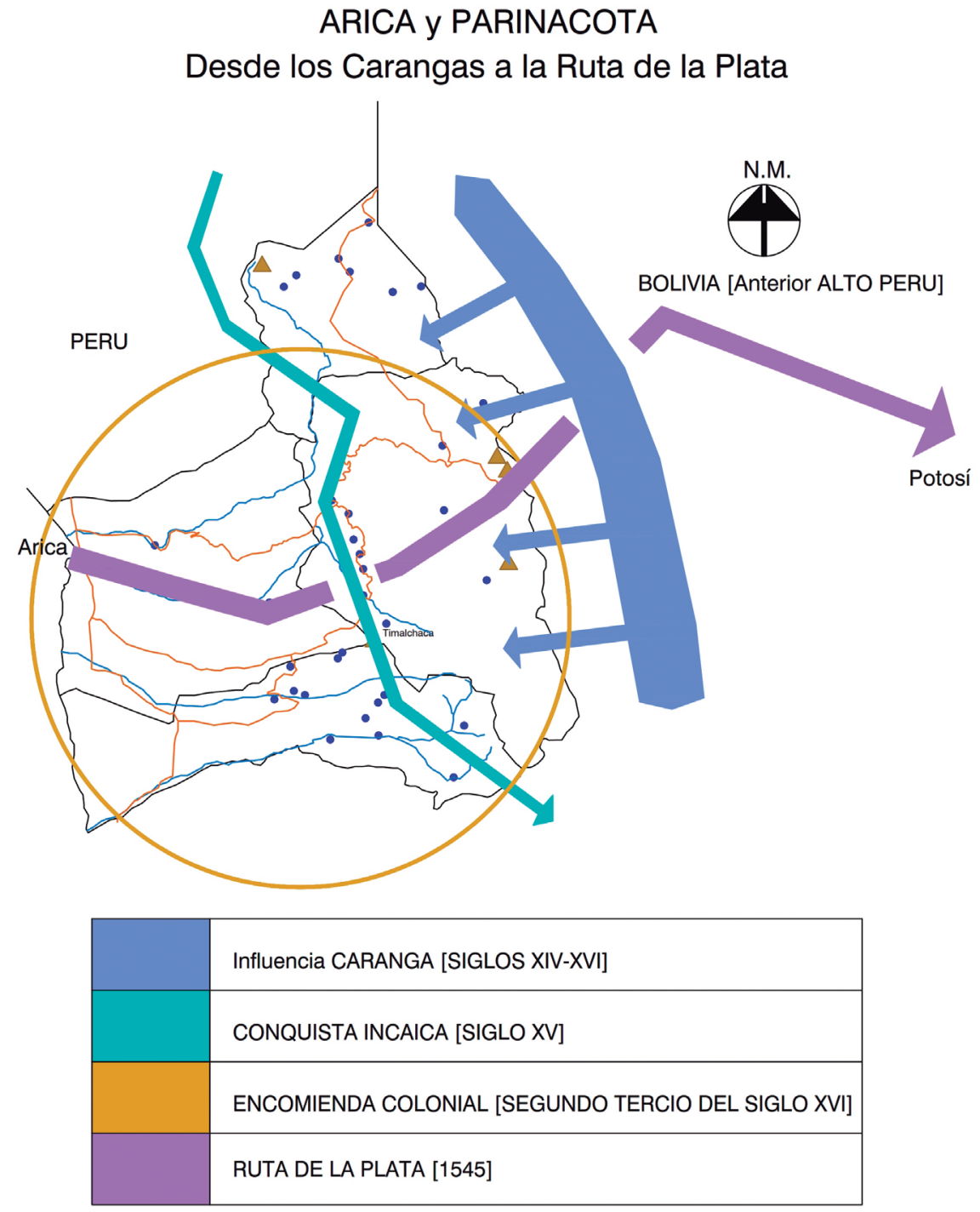

Figura 3. Arica y Parinacota, desde los carangas hasta la Ruta de la Plata Fuente: Ángel Guillén, 2016.
En 1953 se creó el Puerto Libre de Arica y, el 24 de setiembre de 1958, se formó la Junta de Adelanto de Arica (JAA); esta última estuvo vigente hasta 1976. La Junta formaba parte del estado y mantenía autonomía de decisiones para aportar al progreso económico y social de la región. Los síntomas del cambio de paradigma empezaron a notarse en la necesidad de mano de obra, una consecuencia inmediata y determinante del despoblamiento progresivo del entorno rural.

\section{Religiosidad y paisaje}

La sacralización del territorio indígena de Arica y Parinacota ha proseguido a través de los tiempos y, en dicho aspecto, los conjuntos religiosos cristianos aún ocupan un lugar primordial en el escenario de las interacciones simbólicas y aplicativas; trascienden desde su escala arquitectónica a lo urbano y territorial.

Un territorio impregnado de simbolismos es el que encontraron los colonizadores europeos al desembarcar en América; tales patrones culturales, sociales y económicos fueron una referencia ineludible que exigió un trabajo concienzudo para facilitar el arraigo de algunas poblaciones aimaras a este espacio geográfico. 


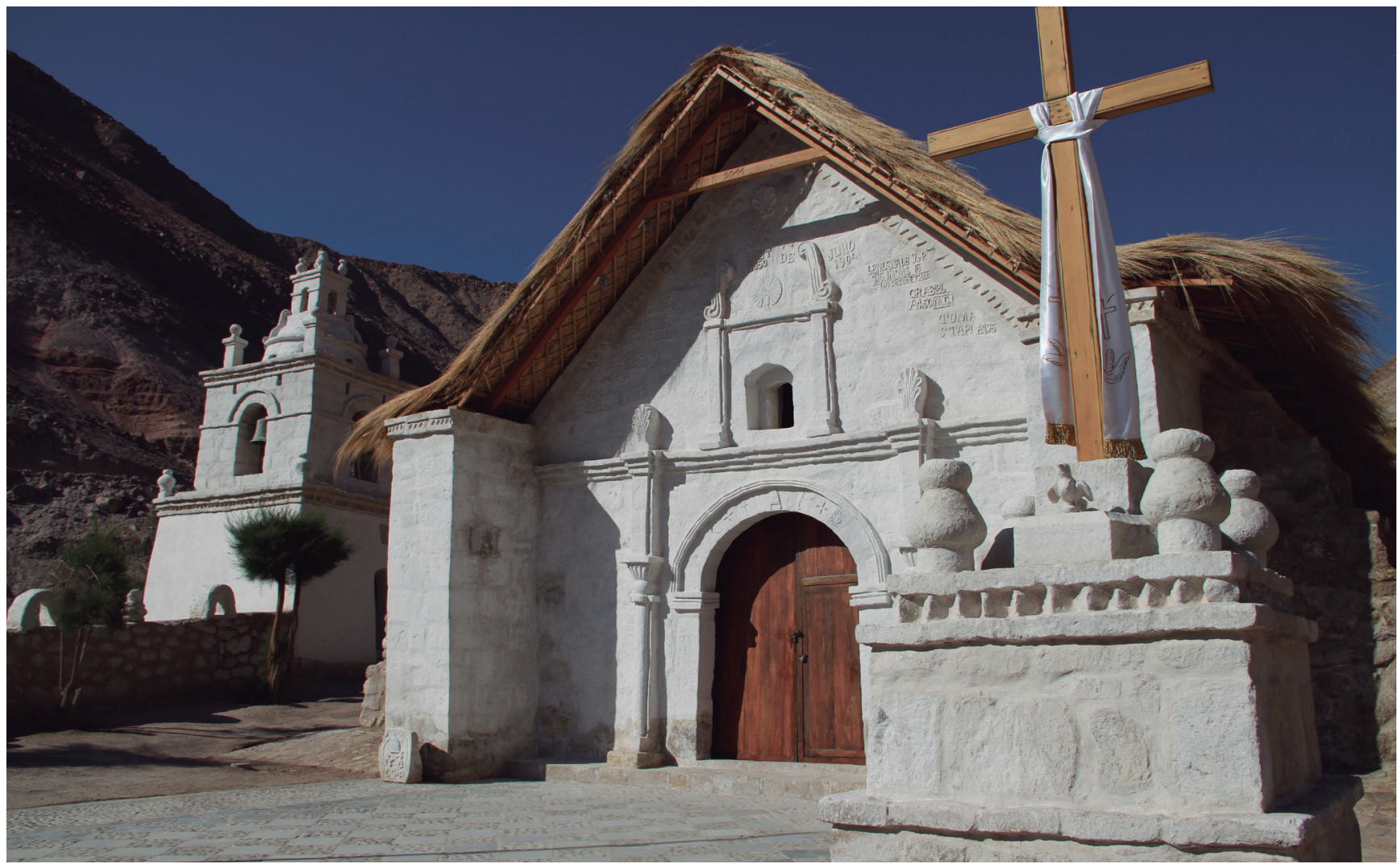

En el Concilio de Trento (1545-1563) se estimó el aporte del arte sacro como un procedimiento de comunicación que debía incorporar posiciones simples y sencillas, argumentadas en la percepción e inclusión de los sentidos.

En términos conceptuales, morfológicos y de emplazamiento, los conjuntos religiosos y cristianos de los altos de Arica sintetizaron desde los albores coloniales un sencillo aspecto que tomó como referencia los aún vigentes conceptos renacentistas y barrocos. Los focos de irradiación arquitectónica y artística en el sur peruano colonial fueron Arequipa, Cusco, Puno, La Paz y Potosí. Los altos de Arica mantuvieron una relación fundamental con los pueblos descritos, y particularmente, desde 1613, con el Obispado de Arequipa.

Un proceso determinante de la época colonial fue el dinamismo ejercido por el circuito de la plata, particularmente en el tramo entre Arica y Potosí, donde se mantuvo una equilibrada economía regional que alentó a los caciques locales en la construcción y mantención de los conjuntos religiosos. Esto permitió la contratación de alarifes y artistas provenientes de latitudes cercanas que generaron, en los altos de Arica, una producción arquitectónica y artística prolífica. Los simbolismos indígenas que existían desde tiempos prehispánicos fueron permanentemente reinterpretados, arquitectónica y artísticamente, durante las fases colonial y republicana (ver Figuras 4 y 5 ).

Dentro y fuera de los templos católicos aún pueden ubicarse aquellos aportes inmanentes de lo territorial que, a escala humana, representan el repertorio cultural indígena: i) tradición y memoria compartida, ii) reivindicación identitaria, iii) valoración del parentesco (familia-linaje), iv) apreciación de una cultura compartida de origen y v) persistencia de 'mayordomías' como una construcción centenaria de valores, que afirman y renuevan los vínculos de la vida con la muerte. Este repertorio, a su vez, está consagrado a través de la teatralización del mundo (mise-en-scène).
Figura 4. Iglesia de Guañacagua restaurada. Ubicada en los valles bajos de Codpa, Comuna de Camarones Fuente: Archivo fotográfico institucional FAMSV, 2016 


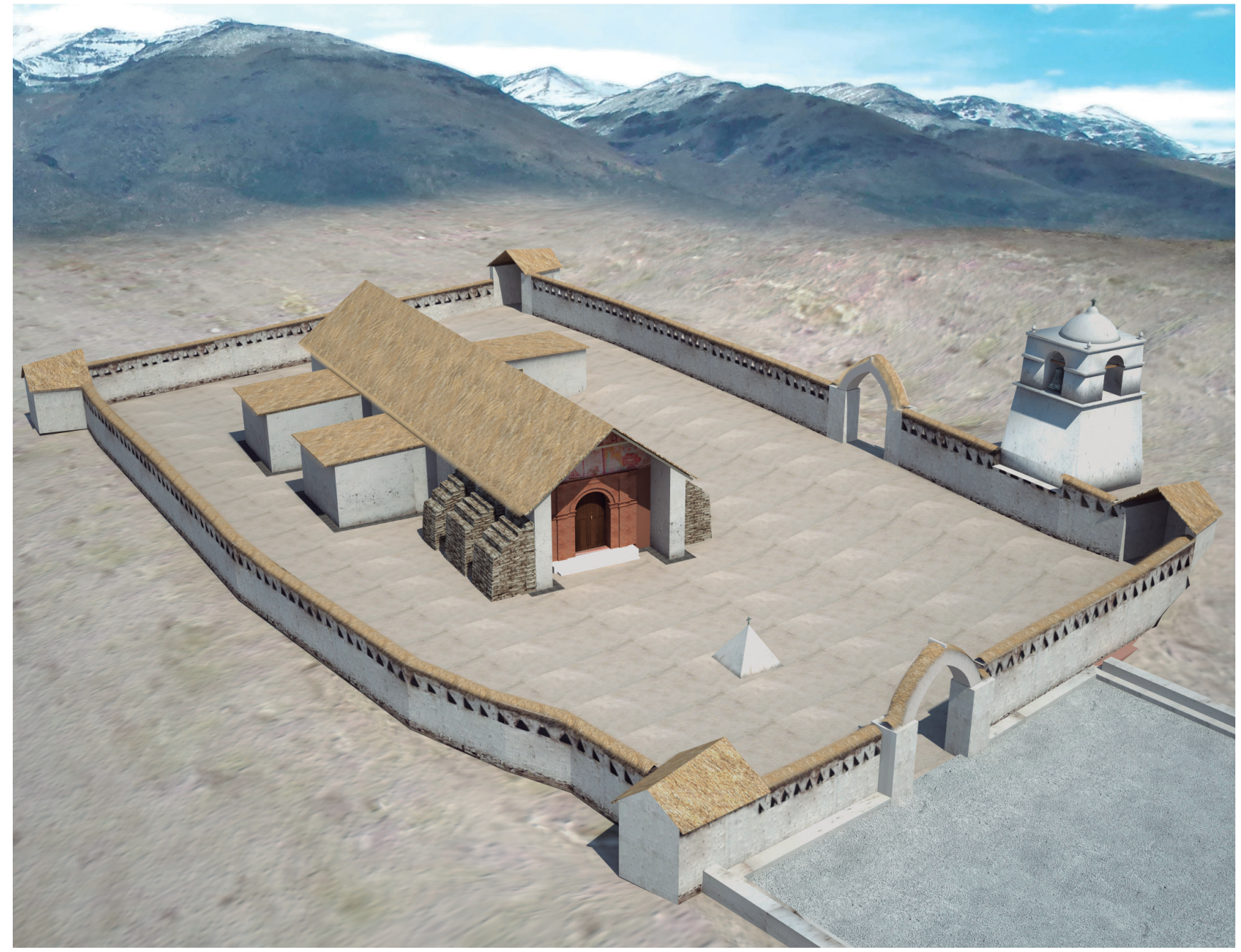

Figura 5. Iglesia San Andrés de Pachama en proceso de restauración. Ubicada en la precordillera, Comuna de Putre

Fuente: Archivo institucional FAMSV, 2016.

Figura 6. Plan Iglesias de Fundación Altiplano MSV: 31 iglesias en proceso de restauración integral, como metodología y proceso patrimonial territorial

Fuente: Archivo fotográfico institucional FAMSV, 2016.
La Iglesia sintetiza el encuentro de todos los mundos y enarbola con acierto el calendario de la vida comunitaria, el que no podría ser auspicioso-efectivo sin la inclusión de la festividad como un acto de fe y legítima esperanza por el devenir. Desde la religiosidad andina podría consolidarse 'la cultura del nosotros' como un enunciado sostenible para afianzar la ritualidad y sabiduría local. Gracias a un efecto multiplicador, la esencia sacra de lo indígena sería entonces capaz de auspiciar proactivamente un modelo de sustentabilidad participativa donde el equilibrio de saberes y poderes generarían un desarrollo legítimo, y duradero.

\section{La Ruta de la Plata como referente cultural-histórico}

Como en ninguna otra región occidental del subcontinente sudamericano, en el espacio geográfico de Arica y Parinacota se han marcado ancestralmente y con fuerza los rasgos del camino, itinerario y/o ruta.

La economía del territorio se tornó palpable con la consolidación temprana del puerto de Arica, situación históricamente coincidente con la presencia occidental y la explotación de los ingentes recursos argentíferos de Potosí a partir de 1545. 

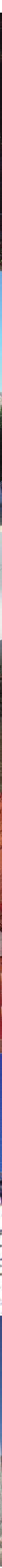


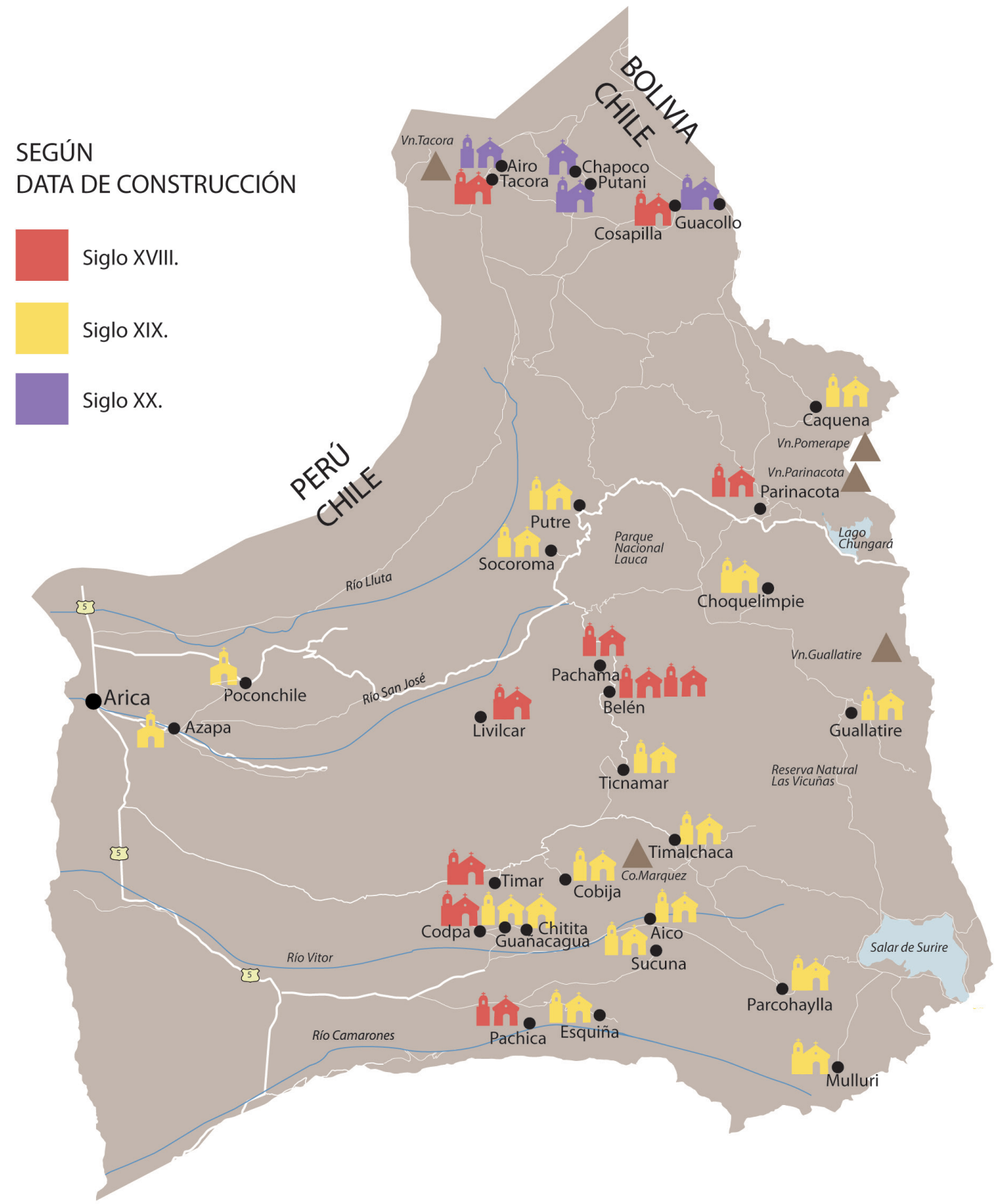

Figura 7. Religiosidad cristiana regional

Fuente: Archivo institucional FAMSV, 2016.
¿Cuáles fueron los beneficios que produjo este 'espacio del trajín' para las poblaciones alto-andinas adyacentes a la Ruta de la Plata?

La Ruta de la Plata, sostenida en la época colonial entre el puerto de Arica y la ciudad de Potosí, significó el fortalecimiento de un circuito comercial que redundó en la articulación territorial del norte chileno y el oeste boliviano. Como no pudo haber sido de otro modo, la vigencia de tales mecanismos de intercambio ocasionó colateralmente una suma de influencias e interacciones. Estas tuvieron, en el campo de la arquitectura religiosa, una contraparte de producciones materiales e inmateriales que aún permanecen como huellas y puntos de apoyo para la implementación de innovadoras iniciativas, las cuales podrían promover el desarrollo sustentable del paisaje cultural de los altos de Arica (ver Figuras 6 y 7 ). 


\section{La XV Región como Paisaje Cultural de América}

La multiplicidad de paisajes culturales de la región Arica y Parinacota fueron combinados, a lo largo de los procesos de adaptación humana, con ciertos imperativos, donde hábitat y recursos ambientales aparecieron configurados en solapamientos y sinergias.

Durante las últimas centurias las poblaciones rurales andinas han sido relegadas sistemáticamente por los gobiernos. La respuesta comunal, en deslinde, supuso un repliegue paulatino hacia su interioridad y un traslado efectivo a la ciudad de Arica en desmedro del carácter dinámico del paisaje. Pese al esfuerzo acometido desde lo endógeno, la integridad del espacio andino expone una faz de asimetría estructural que ha determinado un correlato de letargo extendido. El diagnóstico está expresado en desorden territorial, baja productividad, desplazamiento poblacional, ínfima ocupación laboral y una incomprensible lentitud para adaptarse al manejo de las escalas múltiples.

Las circunstancias morfológicas del espacio andino ariqueño son propicias para incorporar los enfoques de cuenca. Esto tiene como antecedente lo hecho por las culturas originarias, que supieron dominar los contenidos de complementariedad vertical (manejo de pisos ecológicos) y transversalidad; este empeño les proporcionó, además de seguridad alimentaria, los excedentes necesarios para planificar el trabajo y la agricultura. Colateralmente pudieron estimar los diversos riesgos productivos, económicos y sociales, lo que les dio un enfoque prospectivo. Asimismo, la cultura ambiental indígena apeló, como filosofía y praxis, al equilibrio ecológico, principio indesligable de la estabilidad de sus cuencas.

Paisaje y territorio son interdependientes: en ambos casos, existen acuerdos, convenciones y criterios adoptados por los países del orbe para afianzar su visión y manejo como parte de la responsabilidad gubernamental (políticas de estado) en un marco de actuaciones consensuadas (alianzas público-privadas). En esencia, el paisaje cultural es observado como imagen de identidad, 'espejo', y representación del desarrollo, 'reflejo'.

En la actualidad, los paisajes culturales de la Región XV -que conforman un conjunto de subpaisajes longitudinales y transversales que abarcan la integridad de los pisos ecológicos de la geografía ariqueña- exponen disímiles resultados en distintos indicadores. Estos ameritan, obligatoriamente, una serie de respuestas paliatorias para su condición crítica y de urgencia (en el corto plazo), así como propuestas reflexivas ante las demandas actuales conectadas a un turismo demandante de sus potencialidades escenográficas, ancestrales y productivas (en el mediano y largo plazo). Se atraviesa, en consecuencia, por otro decurso histórico en una era diferente, donde el paisaje cultural aparece como el nuevo paradigma patrimonial regional.

\section{Áreas de protección ambiental, y su aporte en la continuidad e identidad del Paisaje Cultural de Arica y Parinacota}

Los solapamientos entre paisajes culturales y reservas ambientales, como en el caso específico de la Sierra del Huaylillas - precordillera de la XV Región-, con los entornos protegidos del Parque Nacional del Lauca, la Reserva Nacional de las Vicuñas y el Monumento Nacional de Surire representan esa interacción imprescindible entre áreas de profundo rigor cultural y espacios de preservación de la biosfera.

Las sinergias históricas entre los paisajes culturales y naturales confirman una convivencia inicialmente armónica y complementaria, lo que se contrapone a otra temporalidad (la actual) menos favorable para la continuidad de ambos tipos de paisaje.

Durante centurias las áreas de reserva ambiental existentes en la XV Región han contribuido escénica y culturalmente al sustento del hombre andino, desde el altiplano hasta los bordes costeros. La economía andina se sostuvo en algún mejor periodo de 


\section{SEGÚN}

\section{ZONA GEOGRÁFICA}

Valles bajos

Hasta 1900 m.s.n.m

Precordillera

Desde 1900 a 3500 m.s.n.m.

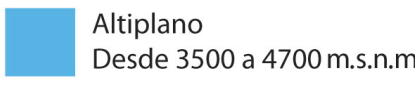

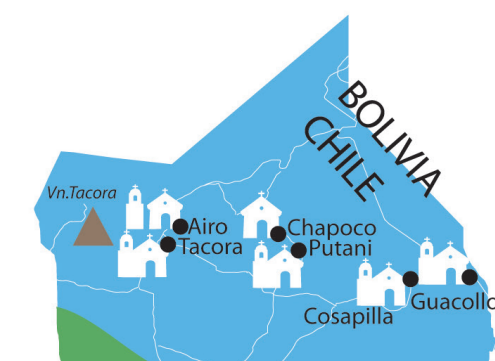

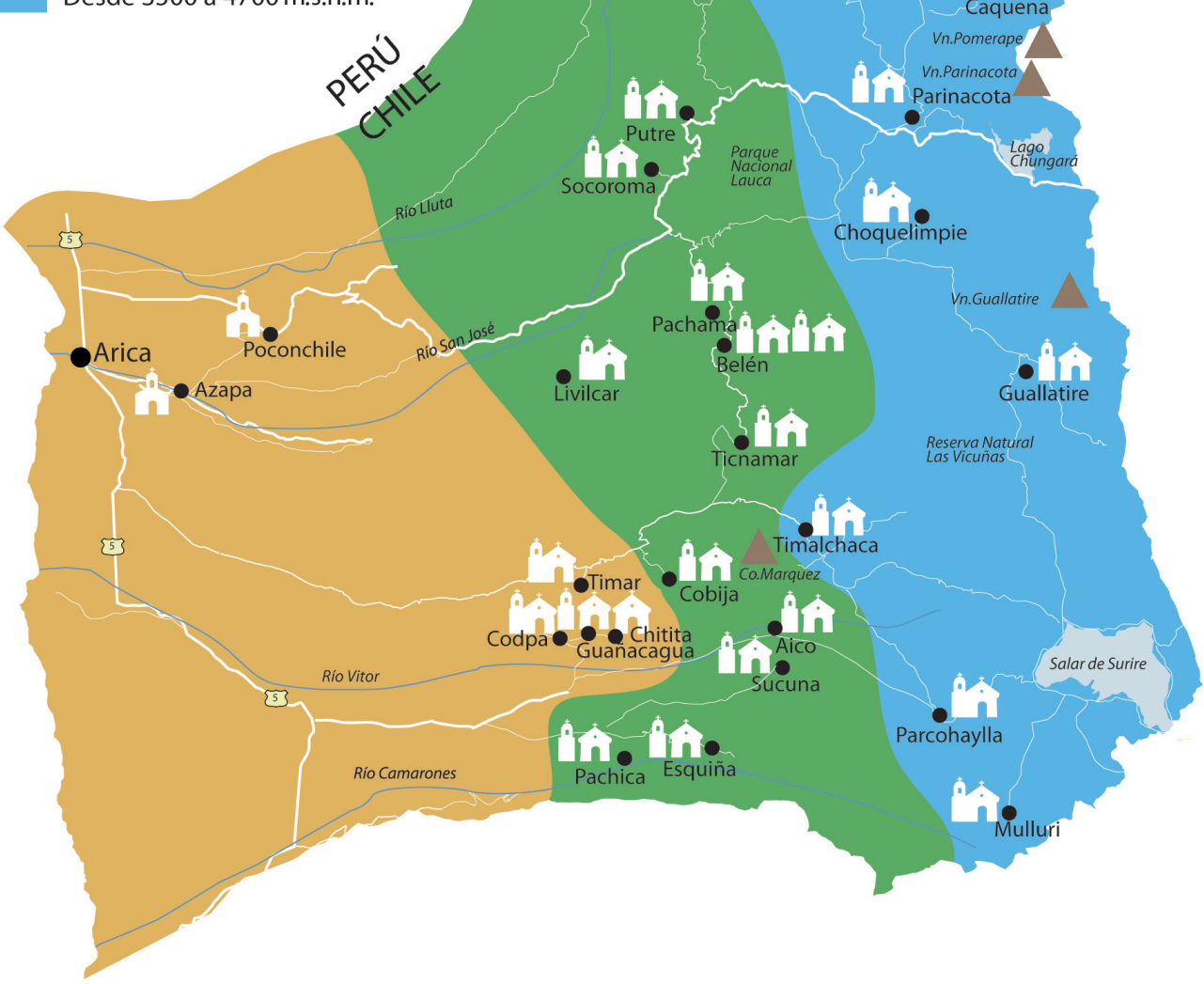

Figura 8. Entornos ecológico ambientales de la XV Región

Fuente: Archivo institucional FAMSV, 2012. su historia en sistemas de intercambio vertical que reforzaron el valor de los pisos ecológicos y sus recursos. En el caso ariqueño, es imposible no reconocer tales valores de coexistencia y mutua necesidad.

En el caso opuesto -el tiempo actual-, se aprecia un deterioro en los niveles de conservación de las áreas naturales, debido, entre otros factores, al descenso poblacional. Tal indicador demuestra lo exigente de la cohabitación entre el hombre y el medio ambiente.

Observado de ese modo, es imposible imaginar la identidad cultural construida por el hombre ariqueño a través de los siglos sin la presencia dinámica de sus entornos ambientales. La pregunta clave e inmersa en incertidumbre sobre la continuidad de 


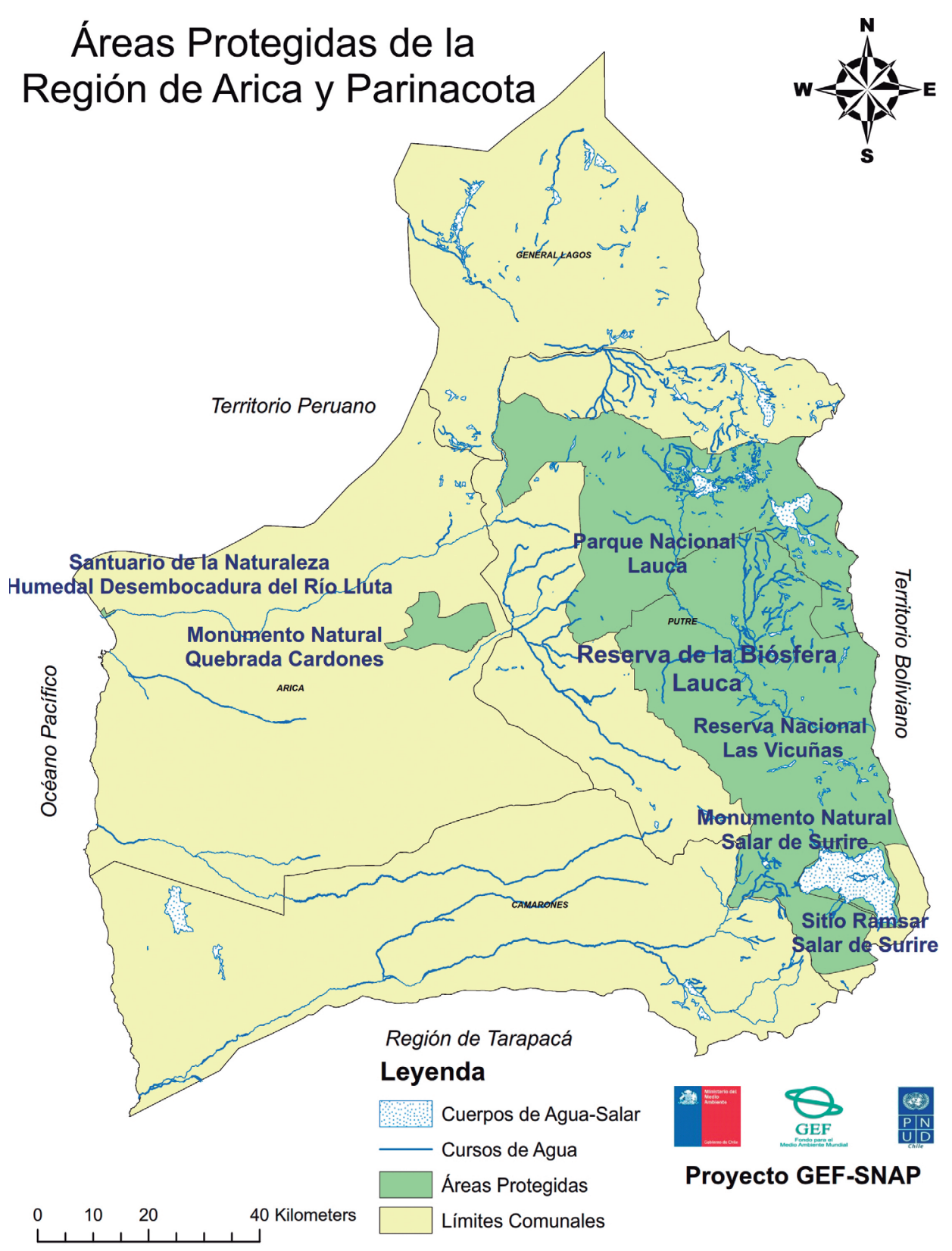

las áreas ambientales y paisajes sería si es suficiente una visión reglamentaria y proteccionista sin una interacción humana mayor.

Específicamente, existen en la región Arica y Parinacota i) el Parque Nacional del Lauca (que además es Reserva de la Biosfera-UNESCO), cuyo ámbito directo de influencia comprende gran parte del macizo andino que limita con Bolivia, el altiplano y la precordillera; ii) la Reserva Nacional de las Vicuñas, la cual, como su nombre lo dice, es un espacio vital para la crianza de camélidos sudamericanos; y iii) el Monumento Nacional Salar de Surire, un testimonio geológico y mineralógico de potencial importancia regional. Además, en las partes altas, intermedias y bajas aparecen indistintamente nevados, lagunas y espejos de agua, así como valles y quebradas, que configuran el paisaje regional.
Figura 9. Áreas protegidas de Arica y Parinacota

Fuente: Archivo Proyecto GEF-SNAP [Sistema Nacional de Áreas Protegidas], 2016. 
devenir Vol. 3, N5, ENERO- JUNIO 2016, PP. 45-66 - ESTUDIOS | ISSN 2312-7570

\section{Subsistema de paisajes culturales regionales}
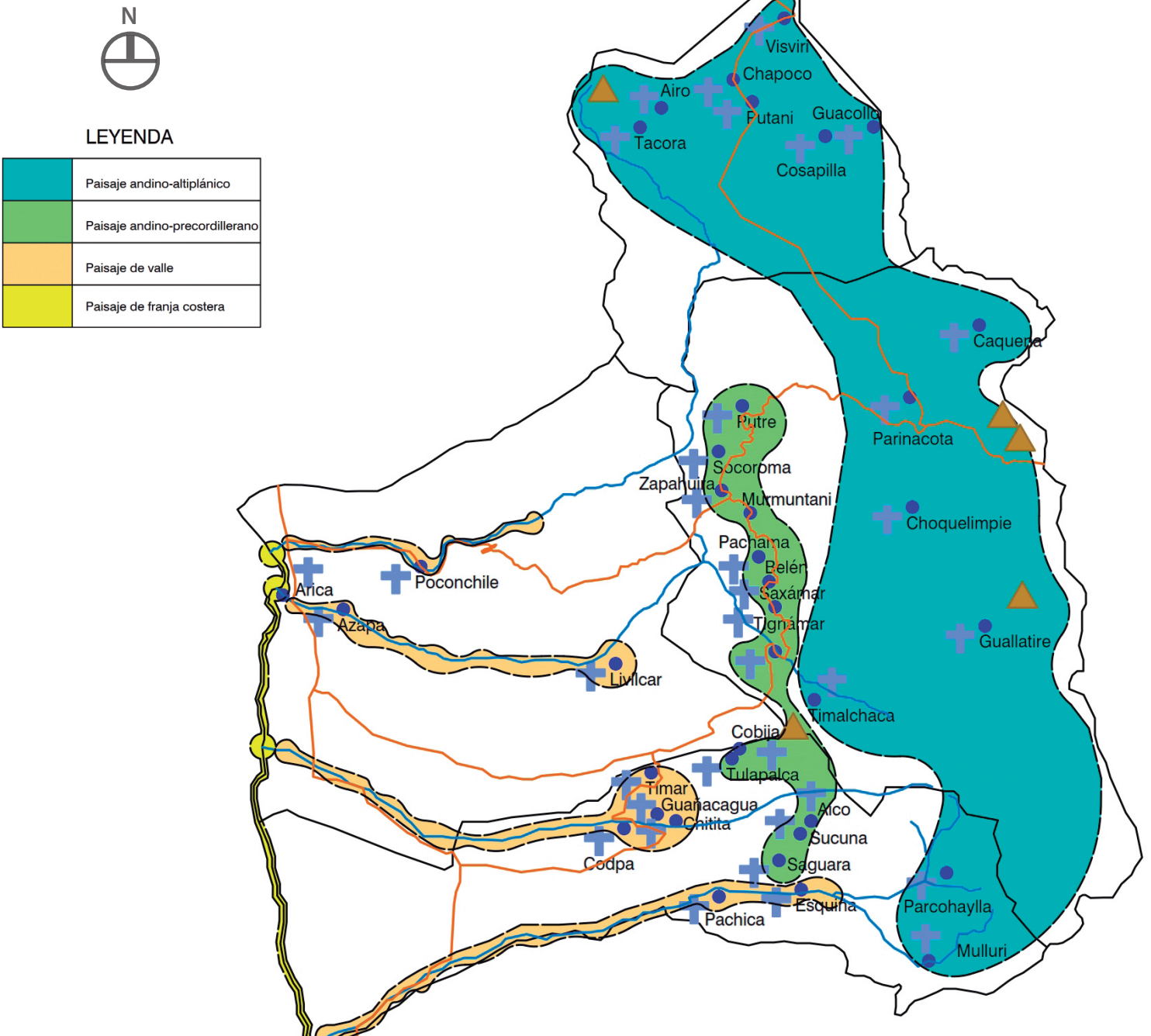

Figura 10. Paisajes culturales de la XV Región

Fuente: Elaboración Ángel Guillén, 2016.

\section{Espacios paisajísticos subregionales}

\section{Borde costero}

Impresiona la belleza de los parajes marítimos caracterizados por costas de ocupación milenaria; son bordes desérticos que exponen las huellas extraviadas del tránsito longitudinal y transversal regional.

\section{Valles}

Conectan la costa con la precordillera y el altiplano. Son espacios articuladores de la transversalidad y complementariedad ecológica. Estos territorios han permitido, en el decurso de los siglos, el cultivo de especies estratégicas que facilitaron el arraigo y la subsistencia de diversos grupos humanos. 


\section{Precordillera}

Entre los 2,000 y 3,500 m.s.n.m. aparece la precordillera de Arica y Parinacota. Es una faja pródiga en vida y productividad auspiciada por la presencia continua de la Sierra del Huaylillas. Representa, históricamente, el espacio de mayores interacciones sociales, culturales y productivas del mundo andino. Esto se debe a que es el ámbito donde se concentró una ingente población originaria, y el escenario proverbial para la adaptación de especies nativas y la domesticación de montañas mediante el uso de terrazas de cultivo.

\section{Altiplano}

El altiplano, gracias a su ubicación geográfica transfronteriza, es el primer punto de aproximación intercultural aimara; su proximidad a territorios bolivianos y peruanos ha permitido una cuantiosa trashumancia, lo que ha llevado a una irradiación cultural e influencias económicas fundamentales a lo largo de centurias. Además, es un espacio fuertemente ligado a la ganadería, que posee montañas emblemáticas con importantes áreas de conservación ambiental.

\section{El paisaje cultural de Arica y Parinacota, y su aporte en el desarrollo terri- torial regional}

El escenario regional de Arica y Parinacota muestra, en conjunto, una potencialidad patrimonial de significativo valor, representada en un paisaje cultural de primer orden dentro del contexto occidental sudamericano.

La ubicación de la XV Región en los últimos lugares de los índices de desarrollo regional de Chile es reveladora. Algo, y mucho, ha sucedido en el espacio-tiempo afrontado; no ha sido necesariamente beneficioso para su presente y futuro. La existencia de un paisaje cultural sorprendente en su aspecto y conformación es una oportunidad concreta para impulsar otra matriz de desarrollo.

Observado de esa forma, la noción del paisaje cultural regional ha debido incorporar conceptos generadores de carácter transversal. El camino en construcción, convertido en un cometido regional, ha puesto en relieve diversos enunciados, declarativos y socializados.

Las acciones en curso dentro de la escala nacional supondrán i) instaurar una política pública nacional de los paisajes culturales, ii) afirmar la condición jurídica del paisaje cultural, iii) impulsar la interacción de autoridades y comunidades involucradas, iv) persistir en los procesos de sensibilización poblacional, v) promover la investigación transdisciplinaria, y vi) encauzar las actividades y proyectos en un plan paisajístico de alcance nacional.

Las fortalezas y debilidades, como siempre, persisten en casa. La resistencia al cambio pone de manifiesto las dificultades de la invitación paisajística. La suerte está echada y si se quiere transformar el paradigma hay que empezar por la región. Con una ruta trazada y tareas en curso puede mostrarse i) la incorporación de la dimensión paisajística andina y rural en las políticas regionales, ii) la vigencia de un conjunto de actuaciones patrimoniales de primer rango nacional e internacional, y iii) la constitución de un paisaje cultural regional con potencial transfronterizo en el entorno aimara de Chile, Bolivia y Perú como Paisaje Cultural de América (ver Figuras 11 y 12).

Tendencias preocupantes del Paisaje Cultural:

- Descenso demográfico que marca la diferencia entre un paisaje vivo (dinámico y proactivo) y un paisaje relicto (ralentizado e inercial)

- In-sustentabilidad y discreta conciencia medioambiental

- Urbanización de la costa (ciudad de Arica) y valles bajos, con un letargo del desarrollo rural 


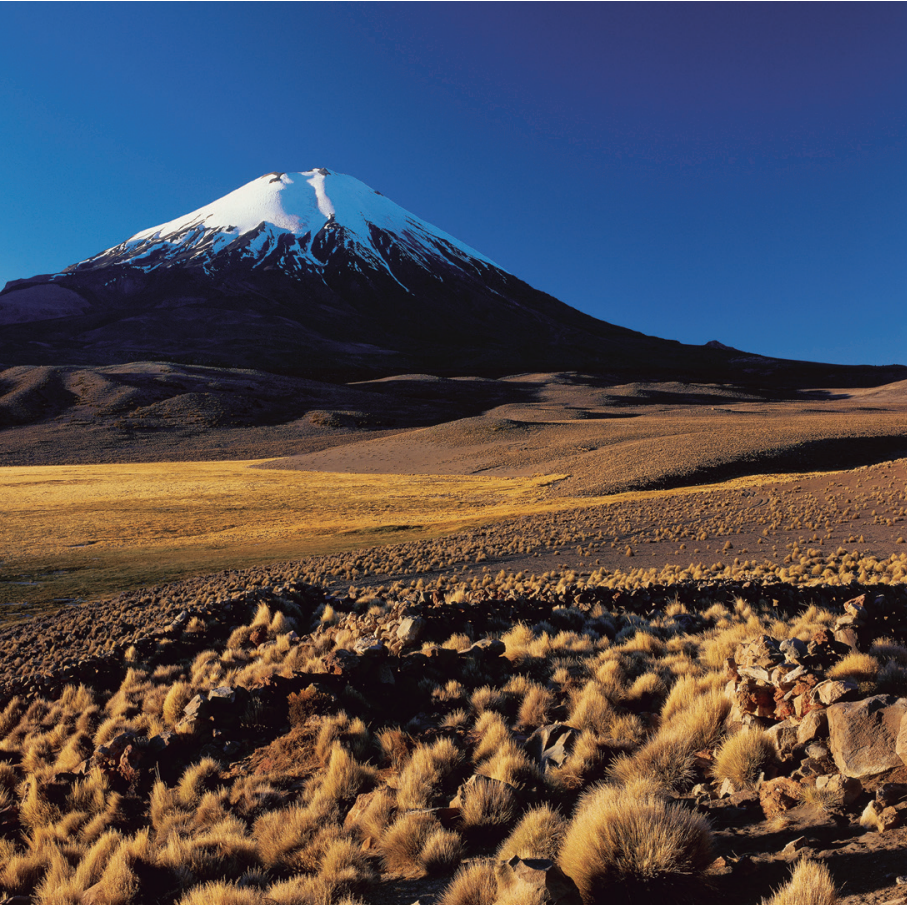

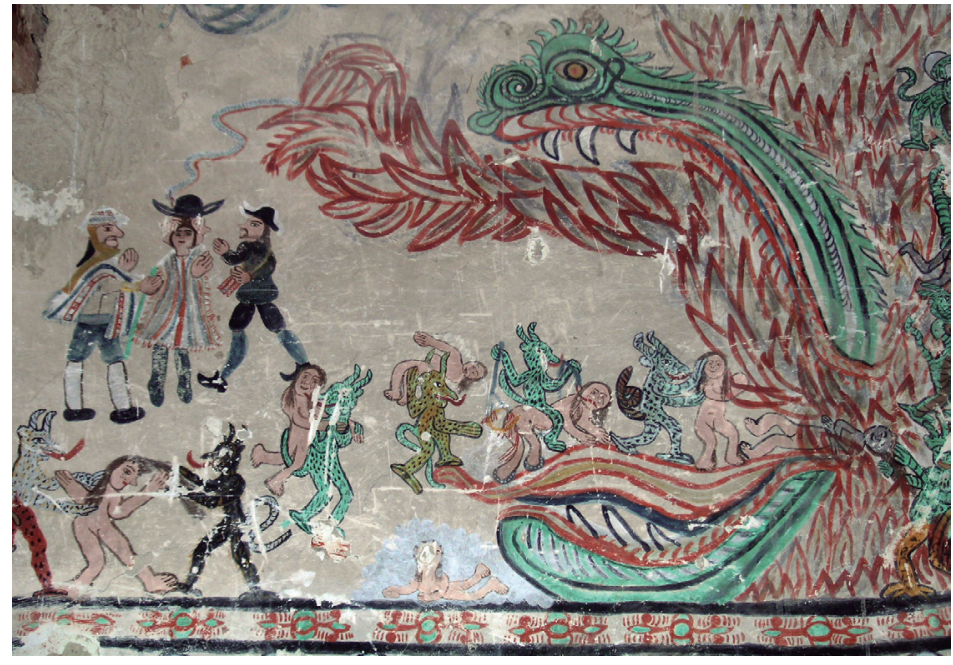

Figura 11. Volcán Parinacota, apu tutelar de las comunidades andinas ariqueñas Fuente: Archivo fotográfico personal Ángel Guillén, 2016.

Figura 12. Pintura mural de la iglesia de Parinacota: una imagen del adoctrinamiento religioso cristiano colonial

Fuente: Archivo fotográfico institucional FAMSV, 2016.

Tareas urgentes en la región Arica y Parinacota, en el contexto del Paisaje Cultural:

- Estructuración de ordenanzas territoriales

- Catalogación del paisaje

- Formulación de la Carta del Paisaje Regional

- Sistematización de la información territorial

- Afianzamiento del programa de Puesta en Valor del Patrimonio (política pública patrimonial)

- Potencialización de los ejes infraestructurales (mejoramiento de la red vial)

- Generación de servicios nuevos e innovadores, y mejoramiento de los existentes

- Consolidación urbano-rural de las comunidades

- Construcción de un paisaje vivo y productivo (no fosilizado), que propicie la asimilación de programas y proyectos futuros

- Preservación del paisaje tradicional, de los conocimientos y la sabiduría aimara

\section{Carácter y propósitos del Paisaje Cultural de Arica y Parinacota}

\section{Visión}

Desarrollar un Paisaje vivo y productivo, facilitador del equilibrio cultural y natural

\section{Misión}

Poner en valor de los recursos existentes en el paisaje cultural, y resaltar el papel histórico y vigente de sus comunidades centenarias

\section{Objetivos}

- Avalar los procesos de conservación de la diversidad cultural y natural de la región Arica y Parinacota 


\section{EI Paisaje Cultural de Arica y Parinacota, dentro de una matriz integrada}

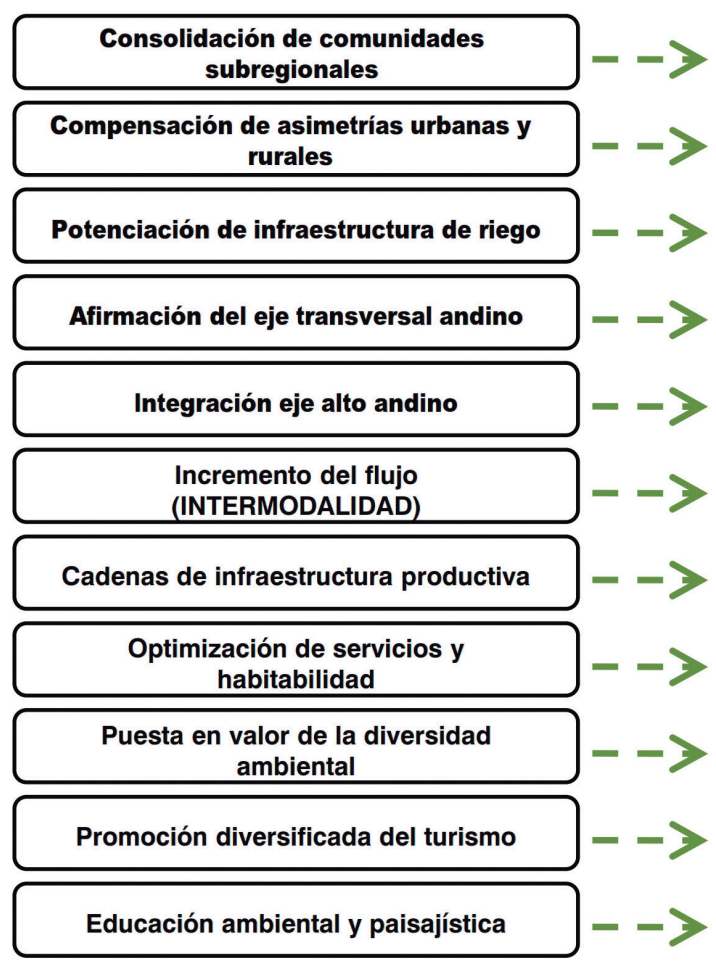

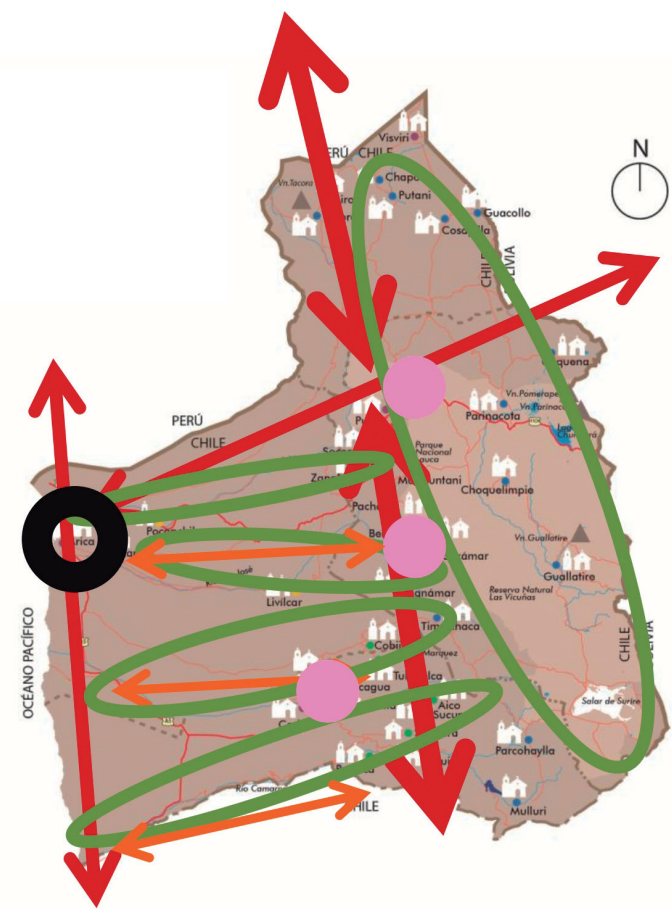

- Vigorizar el espacio territorial regional, a nivel social, físico y productivo

- Rehabilitar la cohesión y equilibrio poblacional de carácter identitario

- Mejorar las capacidades económicas de las poblaciones rurales, de forma que se ponga en relieve su vocación agropecuaria

- Consolidar un circuito turístico de primer orden internacional en base a sus potencialidades ambientales, culturales y naturales

- Desconcentrar la gestión del entorno paisajístico creando unidades descentralizadas y comunitarias

\section{Principios}

- Armonía y complementariedad

- Arraigo e identidad

- Sostenibilidad de los recursos

- Conectividad y transversalidad

- Comunidad participativa

El modelo de gestión paisajístico podría ser de carácter mixto (público-privado) en función de los requerimientos de un coherente fortalecimiento institucional; esto posibilita, en consecuencia, que las políticas públicas paisajísticas sean implementadas, y propicien un entorno armónico, inclusivo e innovador (ver Figura 13).

Los enunciados para la generación de un nuevo paradigma en el Paisaje Cultural de Arica y Parinacota estarían afianzados en i) aportes culturales originarios, sentido de
Figura 13. Paisaje cultural de Arica y Parinacota: su potencial aporte en el desarrollo territorial regional

Fuente: Elaboración Ángel Guillén, 2016. 
identidad, asimilación filosófica de riqueza dentro de la pobreza, cohesión comunitaria y vigencia de la dualidad andina; ii) competitividad; iii) articulación territorial (planes, proyectos y presupuestos); iv) conservación y protección de los recursos naturales; v) consolidación institucional; vi) optimización de la estructura agraria; vii) integración territorial (infraestructura); viii) consensos comunitarios; ix) arraigo poblacional; e x) incremento de la Población Económicamente Activa y mejora del Producto Interno Bruto.

\section{Epílogo}

La confirmación de la dimensión patrimonial de los paisajes ariqueños implica comulgar estratégicamente con sus entornos culturales y naturales. Es necesario formalizar la imbricación entre cultura y naturaleza dentro de un marco de actuaciones públicas (y/o privadas), de tal forma que se asimile al patrimonio como una idea-fuerza fundamental para el ordenamiento territorial. En consecuencia, el análisis patrimonial pasaría de enfocarse en el objeto a enfocarse en el sujeto.

Tal replanteo exige una caracterización precisa del paisaje cultural ariqueño, la cual tendería a precisar objetivos específicos para alcanzar una gestión sistémica y medible. Confirmar los ejes longitudinales y transversales de la geografía regional es necesidad y prioridad para el desarrollo comunitario. Articular al entorno andino como parte protagónica del espacio septentrional fijaría una línea de base para el despegue territorial. Definir el modelo de desarrollo pasa indubitablemente por la valoración efectiva de las vocaciones culturales e históricas del lugar. Propender al aprovechamiento racional de los recursos culturales y naturales sería una medida de previsión y responsabilidad gubernamental. Regenerar la capacidad de atracción territorial redundaría en progresivos retornos humanos, y la reocupación físico-espacial de cuencas y subcuencas. Promover la inclusión y solidaridad como acuerdos y enunciados participativos estimularían el desarrollo compartido. Integrar dispositivos para la innovación y competitividad, desde las políticas públicas paisajísticas, afianzaría los procesos de sustentabilidad espacio-temporal. Estimular las actuaciones públicas y privadas devendría en inversión económica, ocupación laboral y mejora del PBI, medidas imprescindibles para asegurar la vigencia de un paisaje cultural vivo y dinámico. Adoptar decisiones para el desarrollo, en diálogo permanente con la comunidad, potenciaría el sentido democrático de la territorialidad. Anticipar y visualizar la existencia y ocurrencia de desastres naturales y conflictos sociales mitigaría sus impactos directos y colaterales, lo que permitiría la regeneración paisajística y territorial.

La reconversión de los territorios es equivalente a la reinvención de los paisajes culturales. El retorno humano a las cuencas y subcuencas es una apuesta válida para la continuidad de los paisajes: un reconocimiento del arraigo, de la identidad, del patrimonio cultural -material o inmaterial-. En fin, es el reencuentro con el macrolenguaje social.

\section{Referencias}

Fundación Altiplano Monseñor Salas Valdés. (2012). Guía de viaje de Arica y Parinacota, paisaje cultural. Arica, Chile: Autor.

Fundación Altiplano Monseñor Salas Valdés. (2012). Las huellas de la Ruta de la Plata. Santiago, Chile: Autor.

Moreno, R. y Pereira, M. (2011). Arica y Parinacota: la iglesia en la Ruta de la Plata. Santiago, Chile: Altazor.

Murra, J. (2004). El mundo andino, población, medio ambiente y economía. Lima, Perú: Instituto de Estudios Peruanos - Pontificia Universidad Católica del Perú.

Guillén, Á. y Llanque, J. (2011). Bases y estrategias del Plan de Ordenamiento Territorial-Valle del Colca. Arequipa, Perú: Universidad Católica Santa María.

Guillén, Á., Maldonado, L. y Vizcarra, V. (2011). Plan de Acondicionamiento Territorial-Valle del Colca. Arequipa, Lima: Gobierno Regional de Arequipa - Agencia Española de Cooperación Internacional para el Desarrollo. 